\title{
Quantitative Correlation of Large Igneous Provinces and Phanerozoic Extinctions
}

\author{
THEODORE GREEN AND C. BRENHIN KELLER
}

Dartmouth College

Presenting Author: Theodore.K.Green.21@dartmouth.edu

Large Igneous Provinces (LIPs) have long been qualitatively linked with Phanerozoic mass extinctions $[1,2,3]$. Here we quantitatively evaluate this correlation and expand it to include the periods of faunal turnover that define Phanerozoic stage boundaries. Both at the six mass extinctions and across all Phanerozoic stage boundaries, we find a significantly greater than chance relationship between the timing of continental LIP eruptions and periods of faunal turnover. This suggests a causal relationship between continental LIP eruption and biotic crises. We also define a rate threshold that separates continental LIPs known to correlate with mass extinctions from those with less deadly effects. In contrast to continental LIPs, oceanic LIPs are less well correlated with mass extinction, with lower extinction percentages than would be expected to result from a continental LIP of similar eruption rate. We propose that this discrepancy may result in part from diminished degassing of volatiles including $\mathrm{CO}_{2}, \mathrm{SO}_{2}, \mathrm{Cl}$, and $\mathrm{F}$ in submarine LIPs. Though other mass extinction drivers have been proposed, most notably the Chicxulub impactor at the K-Pg, our results suggest volatile emissions from continental LIPs as a major kill mechanism in Phanerozoic biotic crises, including at the big six mass extinctions.

[1] Ernst \& Youbi (2017), Palaeogeography, Palaeoclimatology, Palaeoecology 478, 30-52.

[2] Courtillot \& Renne (2003), Comptes Rendus Geoscience 355, 113-140.

[3] Clapham \& Renne (2019), Annual Review of Earth and Planetary Science 47, 275-303. 